\title{
2003 European Society of Hypertension- European Society of Cardiology Guidelines for the Management of Arterial Hypertension
}

\author{
Sverre Erik Kjeldsen \\ Department of Cardiology, Ullevaal University Hospital, Oslo, Norway; Division of Cardiovascular Medicine, \\ University of Michigan Hospital, Ann Arbor, Mich., USA
}

Hypertension, hypercholesterolemia and smoking are the most important risk factors for cardiovascular disease and death. For the first time, the European sister organizations European Society of Hypertension (ESH) and European Society of Cardiology (ESC) have come out with joint guidelines regarding the detection and treatment of hypertension - printed in this special issue of Heart Drug. It is realized that cardiologists play a key role more than ever in the care of hypertensive patients and an increasingly important role as educators in this field. The Guidelines Paper was developed by experts in the cardiovascular field and key opinion leaders from most countries in Europe. The guidelines are based on the 1999 International Society of Hypertension/World Health Organization Guidelines and they are endorsed by the International Society of Hypertension. It is a thorough educa-

S.E.K. is a member of the Council of the European Society of Hypertension and of the Writing Group of the 2003 European Society of Hypertension-European Society of Cardiology Guidelines.

\begin{tabular}{ll}
\hline KARGER & ( 2004 S. Karger AG, Basel \\
1422-9528/04/0041-0005\$21.00/0 \\
$\begin{array}{l}\text { Fax +4161306 12 34 } \\
\text { E-Mail karger@karger.ch } \\
\text { www.karger.com }\end{array}$ & $\begin{array}{l}\text { Accessible online at: } \\
\text { www.karger.com/hed }\end{array}$
\end{tabular}

tional document with more than 300 quotations of important publications. The new guidelines integrate detection and treatment of other important risk factors, including diabetes. A new issue in the risk assessment of hypertensive patients and for the first time included in the guidelines is the detection of target organ damage like left ventricular hypertrophy, arterial plaque, microalbuminuria or slightly elevated serum creatinine. With a 10 -year risk of cardiovascular disease of $20 \%$ or more, drug treatment for hypertension is always warranted, and a statin and acetylsalicylic acid would usually be indicated. In contrast to the 2003 American Guidelines (JNC-7), in these guidelines, a number of different drugs are considered evidence-based first-line treatment, and combination treatment is strongly recommended to reach blood pressure targets. A shortened 'Practical Guidelines' has been developed and will be translated into various European languages. It is expected that the 2003 ESH-ESC Guidelines will soon be implemented in all countries within the area of the European Union. Hopefully, these clinically oriented guidelines will provide the basis for improved hypertension care and control in Europe!
Sverre Erik Kjeldsen, MD, PhD, FAHA

Department of Cardiology

Ullevaal University Hospital

NO-0407 Oslo (Norway)

Fax+472211 9181, E-Mail sverrkj@frisurf.no 